\title{
Media use and Coping in Tweens during the COVID-19 Pandemic
}

\author{
Nancy A. Jennings $\mathbb{1}^{1} \cdot$ Allison G. Caplovitz ${ }^{2}$
}

Accepted: 22 January 2022 / Published online: 9 February 2022

(c) The Author(s), under exclusive licence to Springer Science+Business Media, LLC, part of Springer Nature 2022

\begin{abstract}
Public and scholarly debate about the effects of media on youth has been a topic of concern since the twentieth century. These concerns were further amplified and accelerated with heavy use of and reliance on media for everyday living and learning with the homebound conditions brought on by the COVID-19 pandemic. With the public discourse about children's media use and school safety concerns, we conducted online interviews of 36 young people ages 9-14 years to learn about (1) their life situations, including school experience, (2) their overall media use, (3) their overall worries and difficulty with their situations, and (4) their stress management and coping strategies during the fall semester of 2020. While tweens reported using media more during the pandemic than before, media did not seem to completely displace other activities. Tweens engaged in media, non-media, and hybrid coping strategies to relieve stress, enhance their mood, and stay connected to others outside their home. This qualitative study was a first step in understanding the effect of COVID-19 on tweens within the context of their coping and resiliency building, and how media factor into these processes.
\end{abstract}

Keywords COVID-19 pandemic $\cdot$ Mental health $\cdot$ Media use $\cdot$ Resilience $\cdot$ Tweens

\section{Highlights}

- The tweens in this study experienced a wide variety of formats for their schooling during the COVID-19 pandemic with most experiencing at least some type of virtual education (hybrid or completely online).

- Tweens were using more media in the fall of 2020 than before the COVID-19 pandemic, and they shared that they use the media as a tool to attend school, to help with schoolwork, to connect with others, and for mood management.

- The most frequently mentioned coping strategy by the tweens involved using media in various ways.

- Hybrid media and non-media strategies were developed such that media enhanced non-media activities.

- The tweens in this study sought a variety of coping strategies which involved media, ignored media, and integrated media.

Public and scholarly debate about the effects of media on children and youth has been a topic of concern since the twentieth century. In a comprehensive literature review of research conducted in the early twentieth century, Wartella and Reeves (1985) documented public discussion and debate about the effects of media on audiences, particularly on children and youth. They noted that each new technology (film, radio, television) brought with it public concerns

Nancy A. Jennings

Nancy.Jennings@uc.edu

1 School of Communication, Film, and Media Studies, University of Cincinnati, Cincinnati, OH, USA

2 Fluent Research, New York, NY, USA and subsequent research about the effects of these devices, particularly with children and youth (Wartella \& Reeves, 1985). These debates have continued in the twenty-first century as more devices are added to media-saturated homes of contemporary families (Mazzarella, 2003, Sternheimer, 2018), and children's media research continues to grow and inform these discussions.

Children's and youth's excessive and frequent use of media has been a continued concern (Hoare et al., 2016, Kim et al., 2020). Parental concerns and subsequent debates about the influence of different devices in children's lives tend to follow the media use behaviors of their children (Jennings \& Wartella, 2013). As a result, concerns about uses of newer technologies (internet, smartphones, and social media) are associated with 8- to 12-year-olds (tweens) and 13- to 18-year-olds (teens) since they are 
heavier users of these devices and technology than younger children (Rideout \& Robb, 2019). Frequent use of and reliance on media for everyday living and learning with the homebound conditions brought on by the COVID-19 pandemic further amplified and accelerated societal concerns about media use for children and youth.

Beginning as early as March 2020, schools in the U.S. began to shutter which sent millions of students home to quarantine, and many in the U.S. never physically returned to school for the rest of the academic year (Map: Coronavirus and School Closures, 2020). Families adjusted to living, working, and learning at home, and screens and technology became even more dominant in family life. By the fall, school districts announced reopening plans with a wide range of approaches. In the 100 largest U.S. school districts, $74 \%$ opened as only remote learning for their instructional model (School Districts' Reopening Plans: A Snapshot, 2020). As a result, screens and technology continued to be a part of daily life for many families around the country.

\section{Media for Coping and Resilience}

Child developmental psychologist Ann Masten (2014) has defined resilience as "the capacity of a dynamic system to adapt successfully to disturbances that threaten system function, viability, or development" (p. 6). While earlier studies of resilience associate media use as a risk factor in coping and resilience building during adversity, more recently technology advances such as text messaging, social media, app-based programs, and virtual reality have been offered as strategies to support resilience, particularly as the study of resilience has become more interdisciplinary (Masten \& Barnes, 2018). Media scholars have begun to investigate these phenomena as well and offer new perspectives on media use and resilience.

Not all scholars are finding negative associations of media use for tweens and teens. Media and technology have also been associated with positive mental health as well. In an extensive review of the literature, Wolfers and Schneider (2020) identified three perspectives on use of media for coping including: (1) stress and coping, (2) mood management and emotion regulation, and (3) media addiction and problematic media use. With a focus on stress, coping, and mood management, the researchers have found that media use is one of the most important and most frequently used coping behavior, and that choices of media content can be used to maintain a good mood, alter a bad mood, or increase or decrease excitement (Wolfers \& Schneider, 2020). Moreover, Reinecke \& Rieger (2021) offered the Recovery and Resilience in Entertaining Media Use $\left(\mathrm{R}^{2} \mathrm{EM}\right)$ Model that connects entertainment media use in the short-term to experiences of recovery and in the long-term as a resilience-enhancing factor.

The COVID-19 pandemic has further amplified the interrelatedness between media use, coping, and mood management, particularly as media use and social isolation increased. Eden and her colleagues (2020) discovered that hope, optimism, and resilience were all predictive of media use, and that media use is closely intertwined with wellbeing among college students. For teens, the increased use of social networking through technology was attributed to more positive outcomes and resilience building (Buzzi et al., 2020). As such, current research suggests the potential for media to be a tool for mood enhancement which is particularly needed in such a challenging and enduring health crisis.

A year after the first schools shuttered in the U.S., we are beginning to understand some of the implications of living conditions during the COVID-19 pandemic. While the growing number of quantitative studies about youth and the pandemic are informative, there is a need for qualitative work to contextualize the range of experiences individuals are having and to make meaning of their experiences. For example, with youth, media, and the pandemic, Fry (2021) calls for research exploring adolescents use of technology and media during the pandemic including the types of media content and engagement that occurred and how media use relates to anxiety, mood management, and worries. Quantitative researchers (Chen et al., 2020, Duan et al., 2020, Ellis et al., 2020, Tang et al., 2020; and Zhou et al., 2020) measure media use by youth and relate this to measurements of anxiety and depression. Yet these studies do not provide insight into how this is experienced, what content youth are encountering, and how they are coping. With a postpositivist approach "documenting contextual influences on social action" (Lindlof \& Tayler, 2011, p. 7), we set out to learn more about how tweens, in particular, were handling the COVID-19 pandemic personally, how they were coping, their resiliency, and what role media played as a part of their pandemic experiences. We had the tween's well-being in mind and approached the study with a commitment to conduct feminist research "not only ABOUT children and their special developmental needs, but also to research WITH children and FOR children" (Lemish, 2013, p. 72).

\section{Tweens, their Media use, and Tween Peer Culture}

Identified as youth between the ages of seven or eight to 13 or 14 years, Cook and Kaiser (2004) describe "tweenhood" as a "aspirational social identity" (p. 206) that is forward looking into adolescence, but they are on the younger side 
with less maturity and more risk taking than older adolescent peers (Strasburger et al., 2009). At the beginning of tweenhood in the U.S., they are the older students at the elementary schools, soon to transition to middle school or junior high school settings, and the oldest tweens may have already moved on to the early years of high school. They become more skilled in abstract thinking and hypothetical reasoning and begin to grow their regulatory competence of moods and responses (Strasburger et al., 2009). As such, tweens are between childhood and adolescence, shifting their attention to their peer culture and away from their parents. For tween and teens, peer culture is often carried out with screens, devices, and media platforms.

Prior to the pandemic, media practices revealed that tweens aged 8 to 12 years self-reported using an average of just under 5 hours of entertainment screen-based media per day (4:44), not including time spent for homework or school (Rideout \& Robb, 2019). Social media use for tweens was not a large part of their media diets. In 2015, it accounted for 16 minutes per day, and no significant change was noted in 2019 when social media accounted for only 10 minutes per day (Rideout, 2015, Rideout \& Robb, 2019). Alternatively, watching online videos, listening to music, and playing video games were the most popular media activities for this age group (Rideout \& Robb, 2019).

Initial reports during the pandemic indicated that media consumption increased for adults and youth (Global Web Index, 2020, Drouin et al., 2020). As a result, researchers at Qustodio (2020) coined the phrase "the COVID effect" to refer to the increase in media-use in the first two months of the COVID-19 pandemic with a documented $130 \%$ increase in the use of entertainment and social apps, and a 50\% increase in educational apps for children between the ages of 4 and 15 years. More recently, Dubit (2021) reported that the pandemic brought about the resurgence of computer and laptop use among youth, particularly for 8- to 15-year-olds. Indeed, in one year's time from October 2019 to October 2020, computer and laptop use for educational purposes increased from 2 hours and 43 minutes to 5 hours and 26 minutes on average for youth 8-10 years, and from 4 hours and 47 minutes to 7 hours and 5 minutes for youth 11-15 years (Dubit, 2021). In addition, during the early days of the pandemic, $30 \%$ of 9- to 13-year-olds around the world reported more use of mobile phones (Götz et al., 2020). Between October 2019 and October 2020, the amount of time children and teens (2-15 years) used tablets increased by $23 \%$ for social media and by $10 \%$ for sending/ receiving messages (Dubit, 2021). The increased use of internet-connected devices has the potential for social connection which is a valuable aspect for development.

For tweens, their peer group becomes an increasingly valued, important, and influential part of their lives. They develop peer culture with one another in which interests, activities, and unique communication modes are shared. Media contributes to peer culture in three important ways: (1) in face-to-face peer culture, (2) in mobile phone peer culture, (3) and over the internet through online peer culture (Lim, 2013). These last two have important implications during the pandemic when face-to-face interactions were not possible. Peer culture became reliant on mobile phone and online communication, contributing to the increased use of screens and devices beyond educational needs for remote learning. With the documented increase in media use, attention turned to the implications of this use on youth.

\section{Media as a Risk Factor for Mental Health}

Even before the pandemic began, the mental health of tweens had become a growing concern, particularly in relationship to media. Researchers have found that anxiety, depression, and other mental health disorders develop in childhood and adolescence, with half of disorders starting by age of 14 years (Kessler et al., 2005). Relatedly, Fors and Barch (2019) noted an association between electronic media use and both anxiety and depression, with a stronger association with depression than anxiety. Specifically, for tweens, video gaming and video chatting were associated with anxiety while video watching was most strongly associated with depression (Fors \& Barch, 2019). An extensive review of the amount of screen time used by adolescents (aged 10-19 years) suggests a positive relationship between depressive symptomatology and screen time for leisure (Hoare et al., 2016). Specifically, high daily time spent with computers and the internet was associated with a higher rate of suicidal ideation and depressive symptoms (Hoare et al., 2016). No studies identified an association between computer and internet use with anxiety, although according to two studies, a higher daily average hours of screen time in general was significantly related to greater severity of anxiety symptoms (Hoare et al., 2016).

However, differences were noted when considering how media were being used, not just how much time they were being used. While calculating the amount of time spent with devices and screens is valuable, scholars recommend considering reframing the discussion of screen use in terms of the type of screen-based activities being done on devices. Rideout (2016) submits that screen usage should be divided into four main categories: (1) passive consumption, (2) interactive consumption, (3) communication, and 4) content creation. When examining these type of categories, key differences have been noted between passive (receiving screen-based messages) and active consumption ("cognitively, socially or physically engaging in screen-based activities that may be reciprocal in nature" (Kim et al., 2020, p. 1470)). For 12- to 17-year-olds, Kim et al. (2020) discovered that 4 or more 
hours of passive consumption of screens per day such as watching $\mathrm{TV}$, videos or movies were related to depression, social phobia, and anxiety whereas active consumption of screens, such as video gaming, chatting, and working on a computer, was not as likely to be associated with these conditions. During the pandemic, general concerns about anxiety and depression continue, and attention has been directed towards media use as a contributing factor. Early quantitative research on children and adolescents revealed that about 1 in 5 children and adolescents (Duan et al., 2020) showed depressive symptoms and 1 in 4 children and adolescents reported anxiety during the early days of the pandemic (Tang et al., 2020). However, older adolescents were more depressed than the younger ones (Chen et al., 2020, Zhou et al., 2020). While several factors contribute to these findings, the role of media and screen use has been called into question. During the COVID-19 pandemic, excessive use of smartphones and the internet (Duan et al., 2020) and social media (Ellis et al., 2020) has been identified as a risk factor for depression in teens.

\section{The Current Study}

In the context of public discourse about children's media use and about school safety concerns during the COVID-19 pandemic, we conducted online interviews of 36 U.S. tweens ages 9-14 years in the Fall of 2020 to learn about (1) their life situations, including school experience, (2) their overall media use, (3) their overall worries and difficulty with their situations, and (4) their stress management and coping strategies during the fall semester of 2020. Informed by existing media research on tweens, resilience theory (Masten, 2014), and media use in resilience and coping (Reineke \& Rieger, 2021, Wolfers \& Schneider, 2020), we explored how tweens were coping with the uncertainty and stress brought by the pandemic and how media and technology use factored into their resiliency by giving voice to the tweens experiencing it. As such, we asked the following research questions:

RQ1: What types of schooling experience did tweens practice?

RQ2: How were tweens using media?

RQ3: How do tweens express their worries, concerns, and difficulties with the COVID-19 pandemic?

RQ4: What type of coping strategies do tweens describe practicing?

\section{Methods}

For this research, we took a feminist media research approach, recognizing that children and youth have "unique needs and skills, as well as a personal voice that deserves to be listened to as well as understood - with respect and empathy" (Lemish, 2013, p. 72). Although we could not conduct in-person interviews due to mitigating practices for COVID-19, we did our best to hear the voice of tweens in the U.S. through online, video-chat interviews that lasted 30- to 45 minutes. Tween participants were interviewed by the two authors using a combination of open- and closedended questions. In the interview, tweens were asked about their COVID-19 pandemic experience thus far regarding four main topics: (1) their life situations, (2) their overall media use, (3) their worries and fears, and (4) their stress management and coping strategies. During the interview, the interviewer was alone in a room in their home. While parents may have assisted the tween to make the initial Zoom connection, the parent would often leave the tween's room once connected for the tween's privacy. Jennings and Caplovitz have each conducted research with children and youth for over 20 years, employing both quantitative and qualitative methods. Both Jennings and Caplovitz are White mothers of tweens and teens.

\section{Study Sample and Data Collection}

Parents and their children were recruited to participate in the study through a combination of convenience sampling and snowball sampling. This strategy consisted of directly emailing or texting parents of tweens in the appropriate agerange known to the researchers as well as posting a recruitment announcement on social media, specifically on the authors' personal Facebook and LinkedIn accounts and also on the Facebook page for the first author's research lab. Recruitment continued throughout the data collection period of October 22 - November 3, 2020 by re-posting announcements on social media. It is important to note the context of the COVID-19 pandemic during the time of data collection. The worldwide case count reached over 40 million and on November 4, the U.S. reported 100,000 new COVID cases in a single day (AJMC, 2021). The death count in the U.S. surpassed 200,000 by November 1 (AS, 2021). The presidential election was imminent and, therefore, there was much talk in the news and from the Centers for Disease Control and Prevention (CDC) about staying safe and reducing transmission during voting (Centers for Disease Control and Prevention Staff, 2020). There were several promising vaccine trials nearing completion and distribution plans were in the works (Gan et al., 2020). In the world of sports, the Dodgers won the World Series, and the Lakers won the NBA finals and fans who celebrated these wins were asked to quarantine for fear of spreading coronavirus (Gan et al., 2020). There were state mask mandates in 33 states and DC as of October 22 (Joo et al., 2021), and while many school districts across the country 
Table 1 Characteristics of tween and parent participants

\begin{tabular}{|c|c|c|}
\hline Characteristics & $N$ & $\%$ \\
\hline \multicolumn{3}{|l|}{ Gender } \\
\hline Boys & 19 & 52.8 \\
\hline Girls & 17 & 47.2 \\
\hline \multicolumn{3}{|l|}{ Age } \\
\hline 9-year-olds & 9 & 25.0 \\
\hline 10-year-olds & 6 & 16.7 \\
\hline 11-year-olds & 3 & 8.3 \\
\hline 12-year-olds & 9 & 25.0 \\
\hline 13-year-olds & 5 & 13.9 \\
\hline 14-year-olds & 4 & 11.1 \\
\hline \multicolumn{3}{|l|}{ Race of tween } \\
\hline White & 26 & 72.2 \\
\hline Multiracial & 4 & 11.1 \\
\hline Latinx & 3 & 8.3 \\
\hline Asian & 1 & 2.8 \\
\hline Undisclosed & 2 & 5.6 \\
\hline \multicolumn{3}{|l|}{ Race of parent } \\
\hline White & 28 & 77.8 \\
\hline Asian & 3 & 8.3 \\
\hline Latinx & 3 & 8.3 \\
\hline Multiracial & 2 & 5.6 \\
\hline \multicolumn{3}{|l|}{ Parent Education Level } \\
\hline Bachelor's degree & 15 & 41.7 \\
\hline Master's degree & 10 & 27.8 \\
\hline Professional or doctoral degree (JD, MD, Ph.D.) & 7 & 19.4 \\
\hline Some college but no degree & 4 & 11.1 \\
\hline \multicolumn{3}{|l|}{ States of family households } \\
\hline Texas & 16 & 44.4 \\
\hline Ohio & 6 & 16.7 \\
\hline Virginia & 6 & 16.7 \\
\hline Illinois & 3 & 8.3 \\
\hline Alaska & 1 & 2.8 \\
\hline Georgia & 1 & 2.8 \\
\hline Massachusetts & 1 & 2.8 \\
\hline New York & 1 & 2.8 \\
\hline Pennsylvania & 1 & 2.8 \\
\hline
\end{tabular}

had plans to resume school in-person, the case rates in the communities often stalled these plans and continued with remote learning (Nierenberg \& Pasick, 2020).

A total of 36 tweens took part in the study, including 19 boys and 17 girls from 9 different U.S. states (See Table 1). They ranged in ages from 9 to 14 years with more 9- and 12-year-olds than other ages. Most parents were mothers with only one father completing the screener. Parentreported race of the tweens and themselves was mostly White (26 and 28, respectively). Parents were highly educated with 32 reporting completion of a bachelor's degree or higher. As such, the sample was rather homogenous with a high proportion of White, highly educated parents, and White tweens.

\section{Measures}

Two primary measures were developed and employed by the researchers: an initial parent screener and a semistructured tween interview. An individual-oriented perspective of data saturation was achieved during the interview process when no new information was generated from probes offered by the researchers (Saunders et al., 2018). The study was approved by the University of Cincinnati's institutional review board.

\section{Parent Screener}

The study's recruitment messaging included a link to a screener survey in which household information could be collected and an online interview could be scheduled with the target tween (See Table 2 for Questions). Upon completion of the screener, parents were contacted to schedule an online interview with their tween.

\section{Tween Interview}

Tween participants were interviewed by the two authors using a semi-structured interview guide with a combination of open- and closed-ended questions. In the interview, tweens were asked about their COVID-19 pandemic experience thus far regarding four main topics: (1) their life situations, including school experience, (2) their overall media use (3) their overall worries and difficulty with their situations, and (4) their stress management and coping strategies (See Table 3 for questions). Caplovitz pretested the interview guide with tween in the age-range of those recruited. Questions that were difficult for the tween to understand or were interrupted differently than expected were modified before conducting the data collection with recruited participants. The questions pertaining to worry and stress reduction were used in a large international study and had been pretested for that study (Götz et al., 2020).

\section{Analysis}

Upon completion of the interviews, the recorded videos were transcribed by a professional transcription service. The authors read, indexed, and sorted through responses of the participants systematically for each question in order to identify emergent themes. As the analysis continued, categories were noted and labeled, and responses from participants were coded by the authors in relation to the categories identified. Themes and categories emerged from the 
Table 2 Parent screener questions

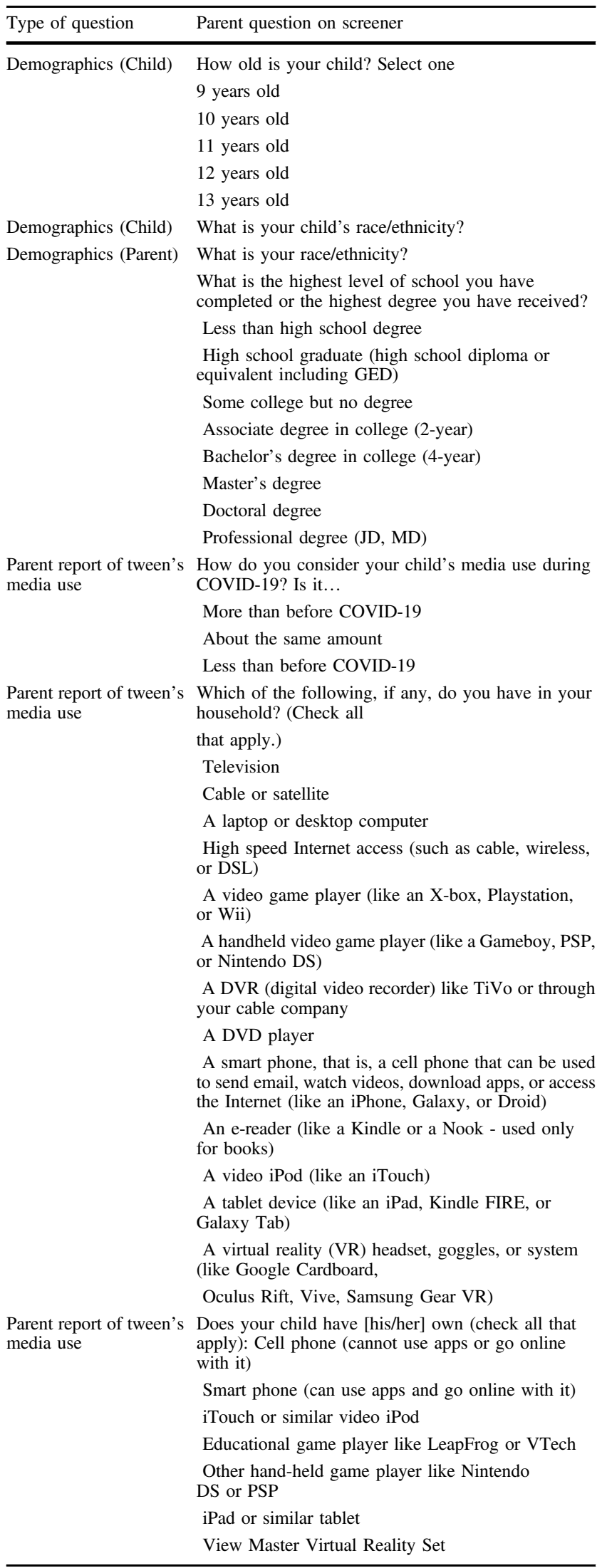

analysis and were agreed upon by consensus of the authors. Any disagreements were discussed by the two authors to better understand how responses may be interpreted and consensus was reached after discussion by the authors. Categories were developed to make meaning and describe the data in relation to the four research questions posed (Spencer et al., 2013). The initial unit of analysis was the complete response from the participant. After further review, smaller units were identified within longer participant responses for more accurate coding of categories. To account for the prevalence of themes and activities, the percentage of tweens (36) expressing themes and activities were calculated using Excel. No computer-assisted qualitative data analysis software packages were used. Moreover, data from the parent screener was also incorporated and tabulated to extract demographic information for the tweens and the types of media present in the home.

\section{Results}

In analyzing the data, key themes emerged in the lives of these tweens dealing with the pandemic and its effects.

\section{RQ1: Virtual, Hybrid, and in-Person School Experiences}

In response to the first research question regarding the tween's school experiences, we found that there were several different ways that participants were attending school. For context, most of the sample (61\%) were going to school completely online. Seventeen percent of the sample were going in-person for most the week and an additional eleven percent explained they were going in person but fully outdoors when the weather permitted. A smaller number $(8 \%)$ explained a hybrid situation where a portion of the day or week they were online and another they were in-person.

When asked to explain their reasons for attending school virtually, most (44\%) talked about trying to stay safe from the virus. One 9-year-old girl explained, "Because I kind of felt like I might get germs if I went to school and I didn't want to have the risk of getting corona." A 12-year-old boy reasoned, "Well, we just decided that it wasn't safe. We want to try to be around our grandparents as much as possible, and my grandpa has breathing difficulties, so I would rather be able to go in person, but we can't this year." A few (22\%) in the sample talked about not having an in-person option available to them. The reasons for attending in-person were either social in nature $(11 \%)$ or that they had trouble or did not like learning virtually (22\%). A 14-year-old boy explained, "I wanted to have the social aspect and meet new people and reconnect with people that I wasn't in contact with over 
Table 3 Tween interview questions

\begin{tabular}{ll}
\hline $\begin{array}{l}\text { Corresponding research } \\
\text { question }\end{array}$ & Question asked of tween \\
\hline RQ1 & Tell me about school. Are you going to the same school as last year? Why \\
or why not. & Are you going virtually or in person? \\
RQ1 & If virtual: How did you decide whether to go virutally? Are you happy \\
& with the decision? [Probe: if it's not open yet] Do you think you will go \\
& back in person this school year? Why or why not? \\
& If in-person: How did you decide whether to go in-person? Are you happy \\
& with the decision? Do you think you will have to go back to virtual learning \\
& this year? Why or why not? \\
& How would you consider your media use during COVID-19? Is it... \\
& More than before COVID-19 \\
RQ2 & About the same amount \\
& Less than before COVID-19 \\
& Thinking about all this media and technology, is there anything you use \\
& more frequently now because of coronavirus (COVID-19)? \\
& Is the whole situation kind of easy or kind of difficult for you? \\
RQ2 & Probe: What makes the situation difficult for you? \\
PQ3 & Probe: What makes the situation easy for you? \\
& On a scale from 1 "not at all" to 6 "very much" \\
How much does the coronavirus (COVID-19) worry you personally? & What are you doing to make things better for yourself? Tell me three \\
strategies you have developed for not getting super stressed out in this \\
situation.
\end{tabular}

quarantine. So, yeah. And I figured it was probably safe enough that it was okay to go in," while a 10-year-old girl explained, "Well, we just thought that it would be better for me and my brother's education, and it'd be easier for us to learn. It's hard for me to learn on Zoom, I found it difficult."

\section{RQ2: Tweens' Media use in the Fall of $\mathbf{2 0 2 0}$}

Regarding the second research question about how tweens were using media during the Fall of 2020, we learned that media permeated the daily lives of the tweens in this sample. Most parents (97\%) reported that their households had at least a television, laptop, high speed internet, a video game console, a streaming service, DVR, DVD, smartphone, and a tablet. In addition, parents reported that their tween had many devices that were personally theirs. More specifically, 27 had their own laptop, 20 had their own video game player, 18 had their own smartphone, 17 had their own tablet, and 9 had their own video game player. While 24 of the parents $(67 \%)$ reported that their tween did not have a social media account before COVID, 13 of them (38\%) allowed their tween to create an account during COVID. The most frequently reported accounts created were TikTok (6), Snapchat (5), and Instagram (2). Most parents (83\%) reported their tween used media more than before COVID, while $17 \%$ reported about the same as before COVID. None reported any less use. Similarly, three quarters of the tweens (74\%) believed that they used more media than before COVID, while only $6 \%$ reported they used less media than before COVID lockdowns. Twenty-one percent thought their media use was about the same as prior to COVID.

When the tweens were asked to explain what media or technology they were using more frequently during COVID, the most common response (39\%) was video chatting (such as Zoom, FaceTime, or Hangouts). One 11-year-old boy listed the many ways he used video chatting. "I use this thing called Blackboard Collaborate for school. I Zoom for junior youth group. I use FaceTime to talk to my family and for piano lessons. I would join the FaceTime call for my birthday. It was fun talking to everyone and they saw me blow up the candles in a rice crispy treat cake thingy." Video chatting served multiple purposes. It also was a way to stay connected to those who do not have phones. A 10-year-old girl explained that she used Google Hangouts to, "call with my friends who don't have actual call or text on their phones." A 12-year-old boy explained, "I used it to communicate with my friends and it just helped me feel more connected. For my friend's birthday, we had a big Zoom call with all of our friends." Other media or technology that was reported to be used more frequently was social media (25\%), in particular TikTok. A 10-year-old girl stated, "I think I use TikTok more than anything else because it seems very entertaining to me to just sit there and scroll through a bunch of videos. But also making stuff, making videos on it." Video game-play was also reported by the tweens to be used more frequently than prior to COVID 
(22\%). When citing video games, one 9-year-old girl also linked play with social interaction. She reported, "I do use Minecraft more than I used to. Because me and my friends get on Zoom and do that after school for fun." Others mentioned they were using their devices such as their computers $(22 \%)$ or phones (14\%) more than before COVID. One 9-year-old boy explained, "[I used] my phone [more] because before COVID I had a lot of activities to do and got out of the house, so I didn't have as much time to be on my phone, but now that I don't really have much to do and I get bored a lot I'm on my phone a lot more." Other media or technology that the sample mentioned with increased use were iPads or tablets $(17 \%)$, YouTube (17\%), TV (14\%), Netflix (8\%), and Discord (6\%).

\section{RQ3: Worry, Concerns, and Difficulty with the COVID-19 Pandemic in the Fall of 2020}

To better understand how much tweens worried about the pandemic and what difficulties they were experiencing, we asked tweens to rate their overall level of worry on a scale from 1 (not at all) to 6 (very much), this sample had a moderate level of worry overall $(M=3.6)$. Similarly, when asked whether "this whole situation" was easy or difficult for them, most tweens in this sample believed it was both (43\%). About a third (31\%) said it was mostly difficult, while about a fourth $(26 \%)$ explained that the situation was mostly easy. Some of the challenges they expressed were that they often got bored or stir-crazy staying inside, they had to distance from people, they had technology challenges, they had nothing to look forward to, or they had difficulty concentrating. One 12-year-old boy explained it as, "Pretty difficult. At least in the spring, I wasn't seeing any one and I didn't have my dog, so I was pretty depressed, and I didn't really have anything to look forward to. And now, it also feels like I don't really have anything to look forward to." A 10-year-old girl said, "Well, it's difficult because sometimes technology doesn't really cooperate and if you are doing school on a computer which most people are, then either the computer can die, there's no internet or something like that. And then the teacher will mark you absent or something and then you'll get a bad grade and then things will just go terribly wrong." Some of the things that they thought were easy about their situations dealing with the virus was that they could pick up new interests, they did not have to get up so early for school, they could connect with family members, friends, and neighbors in new ways, and they could use safety precautions to be more aware of sickness. One 9-yearold boy related, "It's pretty easy because, it's just pretty easy. Because, I don't really have to walk out for school. I just have to walk downstairs, take my Chromebook, put it on my table and join me, which is really easy. So I can sleep in like 30 minutes more," and a 12-year-old boy thought, "I would say for me, it's been pretty easy, because I have people in my house that I could play outside with and distract me from corona. I have friends like that are close to me across the neighborhood, down the street that I can just hang out with."

\section{RQ4: Tweens' Coping Strategies Practiced During the Fall of 2020}

Regarding tweens' coping strategies, we found that while the tweens in this sample were moderately worried, believed that there were difficulties in dealing with their situations, and were mostly at home for school, they also shared a variety of ways that they coped and relieved stress during the pandemic to make their situations more manageable. Some stress-relieving strategies employed by the tweens involved using media, nonmedia, and a hybrid of the two to cope with their situations.

\section{Media Strategies}

Using media was the most common strategy (97\%) employed by the tweens from getting too stressed out. Almost all reported using some form of media as at least one strategy for their resilience. Most often, tweens reported that video games (33\%) provided a way to both unwind as well as to connect with friends. One 14-year-old boy explained, "Definitely playing video games with friends because you can talk to them and interact with them, and not be near them if you have to stay away to cope." Another 14-year-old boy said, "Do something that doesn't have implications on [the virus], like video games." Another way that the tweens met their social needs was through texting, and video chats (22\%) (particularly FaceTime). One 10-year-old boy related that, "Being able to see my family through FaceTime...being able to actually see them through a screen and interact and say hi," was keeping him from getting stressed out. A 13year-old boy said he was, "Facetiming my friends. We have FaceTime almost every day." A 12-year-old girl reported that, "If I maybe feel as if I haven't talked to somebody for a while, or our relationship might be breaking apart a little bit, I just texted them and I say, hey, how are you doing? What's going on in your life? If you need anything, I'm here." Other media strategies reported by some tweens were watching television and movies $(17 \%)$, reading $(17 \%)$, and listening to music $(8 \%)$. A $12-$ year-old boy added that he watched "like a comedy show or comedy movie to get me something to laugh about, like the opposite of worrying." Media was serving as a tool and strategy for keeping them from getting stressed.

\section{Non-media Strategies}

Tweens also reported several non-media strategies. The most common was going outside and exercising (47\%). A 
9-year-old girl explained, "We have two dogs. I like to go on walks with them and we also have an elliptical in the garage. So that also helps me get a little more exercise and makes me feel healthier. Definitely running. I love running. It gets stuff off my mind." A 9-year-old boy said, "There's a high school right beside us. And then like a football field, baseball field. I like going to play like football with my Dad and my brother. And I like to play in our backyard when it snows," and a 12-year-old boy explained, "I am trying to distract myself by playing a lot of sports and hanging out with my neighbors. If I'm worried about it and thinking it's never going to end or just distracting myself with something, I go out and shoot hoops." Another non-media strategy used by mostly girls (10 of 12) was crafting (33\%). A 14-year-old girl explained, "I've [been] doing some crafts and just things at home that'll help keep me occupied." A 10-year-old girl said, "My strategy is just reading, or writing, or painting pictures, drawing, but if I had to list one more, it's designing. I like doing that." Other non-media strategies were spending time with family, friends or neighbors (31\%), playing with an animal (25\%), having a positive mindset (19\%), adhering to COVID safety strategies such as mask-wearing and distancing (19\%), and staying organized with schoolwork (14\%). A 9-year-old explained, "When I get really stressed, I wish I could go out there [to ride horses] because it calms me down. I really like doing it. And out there, I feel safe and happy."

\section{Hybrid of Media and Non-media}

The tweens reported on ways they were using media tools along with non-media tools to make things better for themselves. For example, one 13-year-old boy explained, "I remember where me and my friends we had a FaceTime thing, and we're all at our hoops, and we played like this game of HORSE." A 12-year-old boy said, "I will video chat just like to play Dungeons and Dragons we don't have to drive all the way to someone's house." Through media, they were able to make a non-media activity more engaging and feel more connected to others.

\section{Discussion}

These findings provide a portrait of COVID-19 experiences for tweens - their schooling, media use, worries, and coping strategies - during the fall of the COVID-19 pandemic in 2020 within the U.S. Our goal was to add depth to the lived meaning making of tweens during the time of a public health crisis and give voice to the tweens as they share their perspective on pandemic living. While this is a small, nonrepresentative sample that cannot be generalized to all lived experiences of tweens, it does provide a peek inside the minds and hearts of 36 tweens.

With an eye toward their media use, we learned that these tweens used media as a tool for a variety of different activities and functions during the COVID-19 pandemic. First, media, in particular video chatting and laptops, replaced the physical halls and classrooms of their schools. The classroom became a chat room for over half of the tweens with virtual, remote learning, consistent with increased use of laptops for educational purposes (Dubit, 2021). For some, there was no alternative since physical school buildings were not open, and they seemed to make the most of the situation at hand. In fact, an 11-year-old girl reported, "it's helping my grades a lot because I'm not surrounded by people and feel like I have to do better and them distracting me, I can just sit down and focus." Second, media became a tool for their schoolwork and studies. As a 9-year-old boy explained, "I feel like some things were really helpful. Like the present and the breakout rooms that they added during COVID." Another reported, "now my friend and I will video chat each other to study together for like tests and stuff." Third, devices and the internet made it possible to connect with others outside of their homes. Media served as a way to maintain their peer culture (Lim, 2013) in a COVID-safe way. Whether video chatting to "actually see them [friends] through a screen" or texting to say "hey, how are you doing? What's going on in your life? If you need anything, I'm here," media provided the means to reaffirm the existence of their friends they have not seen in-person, and offer support for one another. Finally, media was a tool for coping with this difficult situation. For a chance to escape with funny TV shows, self-entertain or be creative with TikTok, and just have fun after school with video game play, tweens found ways to relieve stress with media.

While tweens reported using media more during the pandemic than before, media did not seem to completely displace other activities although technology is pervasive in their lives. They used a variety of platforms and devices and found ways that it can support numerous activities such as the 11-year-old boy who used video chatting for school, talking with family, extracurriculars such as piano lessons and youth group, and even birthday celebrations. Media supports rather than displaces activities that would normally be in-person. The hybrid media and non-media coping strategies also suggest that media can enhance activities through connection rather than displace them. For example, the boys played basketball outdoors while using video chat to connect with one another. The video chat made the outdoor activity better by being able to play with friends. Finally, while media was the most frequently mentioned coping strategy consistent with Wolfers \& Schneider, 2020, tweens found numerous ways to de-stress without media. Tweens still went outdoors, exercised, crafted, and played with their pets. All of their time was not spent with media, despite 
the "COVID effect" (Qustodio, 2020). Reinecke and Rieger (2021) also submit that questions remain regarding the efficacy of entertainment media use compared with non-media strategies. While it is unclear which strategies (media, non-media, or hybrid) lead to the greatest benefit, it is clear that these tweens are seeking a variety of strategies which involve media, ignore media, and integrate media. Future research should explore how well these strategies assist in recovery and resilience.

In terms of limitations, it is important to note the lack of racial and parental educational diversity in the sample. The snowball sampling procedure that was used, including the use of social media for recruitment, has the potential to lead to a heterogeneous sample which we experience as the majority of tween participants were White and their parents had a bachelor's degree or higher. COVID-19 has had a disproportionate impact on some racial and ethnic minority groups due to health and social inequities (COVID-19 Racial and Ethnic Health Disparities, 2020). These inequities may also affect access to multiple media platforms, high speed internet, streaming services, and devices that these tweens did not experience.

While these finding cannot be generalized to a large population of tweens, it still provides evidence for practical implications as we consider the living conditions and experiences of tweens during the COVID-19 pandemic. Within the context of concerns about youth's excessive media use (Hoare et al., 2016, Kim et al., 2020), a new perspective needs to be considered, particularly for tweens in the pandemic as they became reliant on media and devices to complete everyday activities such as school and social interactions. Questions still remain about the strength of which type of strategy (media, non-media, or hybrid) is most effective for recovery and resilience (Reinecke \& Rieger, 2021). However, we do have evidence to suggest that, for some tweens, media use assists with mood management and coping as a positive outcome (Wolfers \& Schneider, 2020), and, at times of crisis, stress relief and coping are critical.

\section{Conclusion}

Living through a global pandemic certainly is a stressful situation which requires coping strategies, mood management, emotional regulation, and resilience to overcome the adversity. The tweens do express a moderate level of worry about the pandemic, and some report feeling depressed. At times, media seems to exacerbate the stress when "technology doesn't really cooperate." While at other times, media can help relieve the pressures that the rules of social distancing, remote learning, and mask wearing create. Future research can explore this tension in recovery and resilience (Reinecke and Rieger, 2021) and coping and mood management (Wolfers \& Schneider, 2020), particularly in the content and types of screen time engagement as suggested by Rideout (2016). This qualitative study was a first step in understanding the effect of COVID-19 on tweens within the context of their coping and resiliency building, and how media factor into these processes.

Acknowledgements This work was supported by the Taft Research Center at the University of Cincinnati.

\section{Compliance with Ethical Standards}

Conflict of Interest The authors declare no competing interests.

Publisher's note Springer Nature remains neutral with regard to jurisdictional claims in published maps and institutional affiliations.

\section{References}

AJMC Staff. (2021, January 1). A timeline of COVID-19 developments in 2020. https://www.ajmc.com/view/a-timeline-of-covid19developments-in-2020.

AS English. USA coronavirus: news summary for 1 November (2021, February 11). AS. https://en.as.com/en/2020/11/01/latest_news/ 1604224661_012564.html.

Buzzi, C., Tucci, M., Ciprandi, R., Brambilla, I., Caimmi, S., Ciprandi, G., \& Marseglia, G. L. (2020). The psycho-social effects of COVID-19 on Italian adolescents' attitudes and behaviors. Italian Journal of Pediatrics, 46(69), 1-7. https://doi.org/10.1186/s13052-020-00833-4.

Centers for Disease Control and Prevention Staff (2020). Tips for Voters to Reduce Spread of COVID-19. https://www.cdc.gov/coronavirus/ 2019-ncov/daily-life-coping/going-out/voting-tips.html.

Chen, F., Zheng, D., Liu, J., Gong, Y., Guan, Z., \& Lou, D. (2020). Depression and anxiety among adolescents during COVID-19: A cross-sectional study. Brain, behavior, and immunity, 88, 36-38. https://doi.org/10.1016/j.bbi.2020.05.061.

Cook, D. T., \& Kaiser, S. B. (2004). Betwixt and be tween: age ambiguity and the sexualization of the female consuming subject. Journal of Consumer Culture, 4(2), 203-227. https://doi.org/10. 1177/1469540504043682.

COVID-19 Racial and Ethnic Health Disparities (2020, December 10). CDC. https://www.cdc.gov/coronavirus/2019-ncov/community/ health-equity/racial-ethnic-disparities/index.html.

Duan, L., Shao, X., Wang, Y., Huang, Y., Miao, J., Yang, X., \& Zhu, G. (2020). An investigation of mental health status of children and adolescents in china during the outbreak of COVID-19. Journal of affective disorders, 275, 112-118. https://doi.org/10. 1016/j.jad.2020.06.029.

Dubit Limited. (2021). Dubit Trends Extract: Share of Time 2020 v 2019 United States. https://www.dubitlimited.com/insights/trends.

Drouin, M., McDaniel, B. T., Pater, J., \& Toscos, T. (2020). How Parents and Their Children Used Social Media and Technology at the Beginning of the COVID-19 Pandemic and Associations with Anxiety. Cyber Psychology, Behavior \& Social Networking, https://www.liebertpub.com/doi/pdf/10.1089/cyber.2020.0284.

Eden, A. L., Johnson, B. K., Reinecke, L., \& Grady, S. M. (2020). Media for coping during COVID-19 social distancing: stress, anxiety, and psychological well-being. Frontiers in Psychology, 11, 3388 https://doi.org/10.3389/fpsyg.2020.577639.

Ellis, W. E., Dumas, T. M., \& Forbes, L. M. (2020). Physically isolated but socially connected: psychological adjustment and stress among adolescents during the initial COVID-19 crisis. Canadian Journal of Behavioural Science / Revue canadienne des sciences du comportement, 52(3), 177-187. https://doi.org/10.1037/cbs0000215. 
Fors, P. Q., \& Barch, D. M. (2019). Differential relationships of child anxiety and depression to child report and parent report of electronic media use. Child Psychiatry \& Human Development, 50 (6), 907-917. https://doi.org/10.1007/s10578-019-00892-7.

Fry, C. (2021). Sleep deprived but socially connected: balancing the risks and benefits of adolescent screen time during COVID-19. Journal of Children and Media, 15(1), 37-40. https://doi.org/10. 1080/17482798.2020.1858907.

Gan, N., Renton, A., Reynolds, E., Upright, E., Cotovio, V., Wagner, M., \& Hayes, M. (2020, October 29). October 28 Coronavirus News. CNN. https://www.cnn.com/world/live-news/coronaviruspandemic-10-28-20-intl/index.html.

Global Web Index (April, 2020). Coronavirus Research April 2020 Series 4: Media Consumption and Sport. https://www.globalw ebindex.com/hubfs/1.\%20Coronavirus\%20Research\%20PDFs/ GWI\%20coronavirus\%20findings\%20April\%202020\%20-\% 20Media\%20Consumption\%20(Release\%204).pdf.

Götz, M., Mendel, C., Lemish, D., Jennings, N., Hains, R., ... Yee, A. (2020). Children, COVID-19 and the media: A Study on the Challenges Children are Facing in the 2020 Coronavirus Crisis. TelevIZIon, 33, 4-9. http://www.br-online.de/jugend/izi/english/ publication/televizion/33_2020_E/Goetz_Mendel_LemishChildren_COVID-19_and_the_media.pdf.

Hoare, E., Milton, K., Foster, C., \& Allender, S. (2016). The associations between sedentary behaviour and mental health among adolescents: a systematic review. International journal of behavioral nutrition and physical activity, 13(1), 1-22. https://doi.org/ 10.1186/s12966-016-0432-4.

Jennings, N. \& Wartella, E. (2013). Technology and the family. In A. Vangelisti (Ed.), The handbook of family communication, $2^{\text {nd }}$ Edition (pp. 448-462) Mahwah, NJ: Lawrence Erlbaum Associates.

Joo, H., Miller, G. F., Sunshine, G., Gakh, M., Pike, J., Havers, F. P., Kim, L., Weber, R., Dugmeoglu, S., Watson, C., \& Coronado, F. (2021, February 12). Decline in COVID-19 Hospitalization Growth Rates Associated with Statewide Mask Mandates - 10 States, March-October 2020. Morbidity \& Mortality Weekly Report, CDC, https://www.cdc.gov/mmwr/volumes/70/wr/ mm7006e2.htm\#T1_down.

Kessler, R. C., Berglund, P., Demler, O., Jin, R., Merikangas, K. R., \& Walters, E. E. (2005). Lifetime prevalence and age-of-onset distributions of DSM-IV disorders in the National Comorbidity Survey Replication. Archives of general psychiatry, 62(6), 593-602. https://doi.org/10.1001/archpsyc.62.6.593.

Kim, S., Favotto, L., Halladay, J., Wang, L., Boyle, M. H., \& Georgiades, K. (2020). Differential associations between passive and active forms of screen time and adolescent mood and anxiety disorders. Social psychiatry and psychiatric epidemiology, 55, 1469-1478. https://doi.org/10.1007/s00127-020-01833-9.

Lemish, D. (2013). Feminist theory approaches to the study of children and media. In Lemish, D. (Ed.), The Routledge international handbook of children, adolescents and media (pp. 68-74). Routledge.

Lim, S. S. (2013). Media and peer culture: Young people sharing norms and collective identities with and through media. In Lemish, D. (Ed.), The Routledge international handbook of children, adolescents and media (pp. 322-328). Routledge.

Lindlof, T. R., \& Taylor, B. C. (2011). Qualitative communication research methods (third edition). Sage publications.

Map: Coronavirus and School Closures (2020, March 6). Education Week. https://www.edweek.org/ew/section/multimedia/map-corona virus-and-school-closures.html.

Masten, A. S. (2014). Global perspectives on resilience in children and youth. Child Development, 85(1), 6-20. https://doi.org/10.1111/ cdev.12205.
Masten, A. S., \& Barnes, A. J. (2018). Resilience in Children: Developmental Perspectives. Children (Basel, Switzerland), 5(7), 98. https://doi.org/10.3390/children5070098.

Mazzarella, S. (2003). Constructing youth: Media, youth, and the politics of representation. In Valdivia, A. N. (Ed.) A Companion to Media Studies. (pp. 227-246). Blackwell Publishing.

Nierenberg, A., \& Pasick, A. (2020, November 11). Will any more schools reopen in 2020? New York Times. https://www.nytimes. com/2020/11/11/us/will-any-more-schools-reopen-in-2020.html.

Qustodio (2020). Connected more than ever. https://qweb.cdn.prismic.io/ qweb/e59c2e0f-ef4f-4598-b330-10c430e2ec71_Qustodio+2020 + Annual+Report + on+Children\%27s + Digital+Habits.pdf.

Reinecke, L. \& Rieger, D. (2021). Media Entertainment as a SelfRegulatory Resource: The Recovery and Resilience in Entertaining Media Use (R²EM) Model. In Vorderer, P., \& Klimmt, C. (Eds.). The Oxford handbook of entertainment theory. Oxford University Press. https://doi.org/10.1093/oxfordhb/9780190072216.013.39.

Rideout, V. (2015). The Common Sense census: Media use by tweens and teens, 2015. Common Sense Media. https://www. commonsensemedia.org/sites/default/files/uploads/research/ census_researchreport.pdf.

Rideout, V. (2016). Measuring time spent with media: the Common Sense census of media use by US 8-to 18-year-olds. Journal of Children and Media, 10(1), 138-144. https://doi.org/10.1080/ 17482798.2016.1129808.

Rideout, V., \& Robb, M. B. (2019). The Common Sense census: Media use by tweens and teens, 2019. Common Sense Media. https://www.commonsensemedia.org/sites/default/files/uploads/ research/2019-census-8-to-18-full-report-updated.pdf.

Saunders, B., Sim, J., Kingstone, T., Baker, S., Waterfield, J., Bartlam, B., \& Jinks, C. (2018). Saturation in qualitative research: exploring its conceptualization and operationalization. Quality \& quantity, 52(4), 1893-1907. https://doi.org/10.1007/s11135-0170574-8.

School Districts' Reopening Plans: A Snapshot. (2020, October 16). Education Week. https://www.edweek.org/leadership/schooldistricts-reopening-plans-a-snapshot/2020/07.

Spencer, L., Ritchie, J., Orston, R., O'Connor, W., \& Barnard, M. (2013). Analysis: practices, principles and processes. In Ritchie, J., Lewis, J., Nicholls, C. M., \& Ormston, R. (Eds.). Qualitative research practice: A guide for social science students and researchers, $2^{\text {nd }}$ Edition, (pp. 269-294), Sage.

Sternheimer, K. (2018). Connecting social problems and popular culture: Why media is not the answer (Second Edition). Routledge.

Strasburger, V. C., Wilson, B. J., \& Jordan, A. B. (2009). Children, adolescents, and the media. Sage.

Tang, S., Xiang, M., Cheung, T., \& Xiang, Y. T. (2020). Mental health and its correlates among children and adolescents during COVID19 school closure: The importance of parent-child discussion. Journal of affective disorders, 279, 353-360. https://doi.org/10. 1016/j.jad.2020.10.016.

Wartella, E., \& Reeves, B. (1985). Historical trends in research on children and the media: 1900-1960. Journal of Communication. https://doi.org/10.1111/j.1460-2466.1985.tb02238.x.

Wolfers, L. N., \& Schneider, F. M. (2020). Using media for coping: a scoping review. Communication Research, 0093650220939778.

Zhou, S. J., Zhang, L. G., Wang, L. L., Guo, Z. C., Wang, J. Q., Chen, J. C., \& Chen, J. X. (2020). Prevalence and socio-demographic correlates of psychological health problems in Chinese adolescents during the outbreak of COVID-19. European Child \& Adolescent Psychiatry, 29(6), 749-758. https://doi.org/10.1007/ s00787-020-01541-4. 